\title{
Mortality and its association with CD4 cell count and hemoglobin level among children on antiretroviral therapy in Ethiopia: a systematic review and meta- analysis
}

\author{
Chalachew Adugna Wubneh* (iD and Getaneh Mulualem Belay
}

\begin{abstract}
Background: Even though there are advancements in HIV/AIDS prevention and treatment approach, HIV continues to be a global challenge. Pediatrics HIV is one of the challenges in the reduction of child mortality particularly in less developed countries like Ethiopia. Therefore, this study aims to estimate the pooled proportion of child mortality and the effect of hemoglobin level and CD4 cell count among children on antiretroviral therapy in Ethiopia.

Method: All published were articles searched using PubMed, EMBASE, Google Scholar, and Web of Science database. Besides, Ethiopian institutional research repositories and reference lists of included studies were used. We limited the searching to studies conducted in Ethiopia and written in the English language. Studies that were done in a cohort, crosssectional, and case-control study design were considered for the review. The weighted inverse variance random effects model was applied, and the overall variations between studies were checked by using heterogeneity test Higgins's $\left(P^{2}\right)$. Subgroup analysis by region and year of publication was conducted. All of the included articles were assessed using the Joanna Briggs Institute (JBI) quality appraisal criteria. In addition, publication bias was also checked with Egger's regression test and the funnel plot. Based on the results, trim and fill analysis was performed to manage the publication bias.
\end{abstract}

Result: A total of 16 studies with 7047 participants were included in this systematic review and meta-analysis. The overall pooled proportion of mortality among children on antiretroviral therapy (ART) was found to be $11.78 \%(95 \% \mathrm{Cl} 9.34$, 14.23). In subgroup analysis, the highest child mortality was observed in the Amhara region $16.76 \%(95 \% \mathrm{Cl} 9.63,23.90)$ and the lowest is in the Tigray region $4.81 \%(95 \% \mathrm{Cl} 2.75,6.87)$. Besides, the proportion of mortality among children with low CD4 count and hemoglobin level was $2.42(\mathrm{AOR}=2.42,95 \% \mathrm{Cl} 1.65,3.56)$ and $3.24(\mathrm{AOR}=3.24,95 \% \mathrm{Cl} 1.51,6.93)$ times higher compared to their counterparts, respectively.

Conclusion: The proportion of mortality among children on ART was high in Ethiopia. Those children who had low CD4 cell count and low hemoglobin levels at baseline need special attention, treatment, and care.

Trial registration: The protocol of this systematic review and meta-analysis has been registered in PROSPERO with the registration number CRD42018113077.

Keywords: ART, CD4, Children, Ethiopia, Hemoglobin, Meta-analysis, Mortality, Systematic review

\footnotetext{
* Correspondence: mekidem21@gmail.com

Department of Pediatrics and Child Health Nursing, School of Nursing,

College of Medicine and Health Sciences, University of Gondar, Gondar,

Ethiopia
}

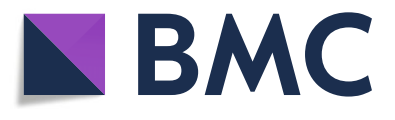

() The Author(s). 2020 Open Access This article is licensed under a Creative Commons Attribution 4.0 International License, which permits use, sharing, adaptation, distribution and reproduction in any medium or format, as long as you give appropriate credit to the original author(s) and the source, provide a link to the Creative Commons licence, and indicate if changes were made. The images or other third party material in this article are included in the article's Creative Commons licence, unless indicated otherwise in a credit line to the material. If material is not included in the article's Creative Commons licence and your intended use is not permitted by statutory regulation or exceeds the permitted use, you will need to obtain permission directly from the copyright holder. To view a copy of this licence, visit http://creativecommons.org/licenses/by/4.0/. 


\section{Background}

Human immunodeficiency virus (HIV) is one of the global pandemic infectious diseases that cause major survival challenges of humankind. Globally, 37.9 million people are living with HIV by the end of 2018; of these 20.6 million lives in eastern and South Africa, 1.7 million people acquired new HIV infection and 160,000 were infants [1]. Worldwide in 2018, 770,000 peoples died from HIV-related causes [2]. One of the major challenges in child morbidity and mortality reduction is pediatric HIV [3]. According to the World Health Organization (WHO) report in 2019, 89\% of low- and middle-income countries, including Ethiopia, has adopted treat all strategies for children from the international policy $[4,5]$. As a result, the introduction of this highly active antiretroviral therapy (HAART) significantly reduced HIV-related mortality and morbidity among children infected with HIV [6-10]. According to global estimation, 1.7 million children under the age of 15 years were living with HIV and 100,000 children died with acquired immune deficiency syndrome (AIDS)-related causes [11]. Although significant progress has been made in the accessibility of ART and improved program implementation, child mortality even after ART initiation is a challenge for Africa including Ethiopia [12-14]. Different observational studies have been conducted so far in different parts of Ethiopia with variation in time and place. Those studies have reported the magnitude and predictors of mortality among children taking ART. But there is inconsistency in the magnitude and predictors of mortality. Especially, the effect of baseline hemoglobin and low CD4 cell count on child mortality after the initiation of ART is an important issue to be studied. These predictors were reported as statistically significant in some studies, whereas in other studies, they were not significant. Besides, in sub-Saharan Africa (SSA), including Ethiopia, one systemic review and meta-analysis had been conducted on the proportion of child mortality [14], but there was no national study which assesses on the proportion of child mortality and the effect of baseline hemoglobin and CD4 cell count on the child mortality. Therefore, this systemic review and metaanalysis aims to estimate the national magnitude of child mortality after ART initiation and its association with baseline hemoglobin and CD4 cell count in Ethiopia.

\section{Method}

\section{Reporting}

To report the findings of this systematic review and meta-analysis, the Preferred Reporting Items for Systematic Review and Meta-analysis (PRISMA) guideline was used [15] (Additional file 1). The protocol of this study was registered in PROSPERO with a registration number of CRD42018113077.

\section{Databases and search strategy}

An advanced search was carried out in electronic databases including, PubMed, EMBASE, Web of Science, and Google Scholar. In addition, Ethiopian university research repository, gray literature from Google, and reference lists of included studies were searched. Moreover, we searched studies manually. We had been searching for articles until April 15, 2020. The search focused on the studies that reported the proportion of mortality among children on ART and/or its association with at least hemoglobin and/or CD4 count. The searching was conducted using the following terms and/or phrases: "Mortality," "Death," "Treatment outcome," "Survival," "Attrition," "HIV," "Human Immune Deficiency Virus, " " Acquired Immune Deficiency Syndrome," "ART," "Antiretroviral Therapy," "Highly Active Antiretroviral Therapy," "Prevalence," "Proportion," "Associated Factors," "Predictors," "Hemoglobin," "Hgb," "CD4 Count," "Children," "Child," "Pediatrics," "Paediatrics," "Infant," " Neonates," and " Ethiopia." The searching strings were developed by using "AND" and "OR" Boolean operators (Additional file 2).

\section{Inclusion and exclusion criteria}

We have included the studies if they fulfill the following inclusion criteria: (1) studies conducted in Ethiopia (2); studies conducted on children $<15$ years of age (3); observational studies, including cross-sectional, cohort, and case-control studies (4); studies that reported proportion of mortality and/or at least its association with hemoglobin and/or CD4 count (5); the outcome was the proportion of mortality among children on ART; and (6) studies published in the English language. On the other hand, qualitative studies, trials, and citations without full-text were excluded.

\section{Quality assessment and study selection}

To remove duplicated studies, the Endnote version 7 (Thomson Reuters, London) reference manager was used. Two reviewers (CAW and GMB) independently screened the titles and abstracts to consider the articles in the fulltext review. Two investigators (CAW and GMB) assessed the quality of the studies using Joanna Briggs Institute quality appraisal criteria (JBI) [15]. The JBI critical appraisal checklist for cohort studies was employed (Additional file 3 ). The discrepancy was solved by consensus. Studies that got $50 \%$ and above of the quality scale were considered low risk and included in the meta-analysis.

\section{Data extraction}

Two independent investigators (CAW and GMB) extracted the data. Any disagreement was solved by repeating the procedure. Information about the first author and year of publication, study region, setting, design, population, sample size, follow-up period, the proportion of 
mortality, and the odds ratio of hemoglobin and CD4 count were extracted.

\section{Summary measures}

Child mortality in this systematic review and meta-analysis was considered as the death of confirmed HIV-positive children after ART started as described in the primary articles. Anemia at baseline was defined as low hemoglobin level less than $10 \mathrm{~g} / \mathrm{dl}$. Low CD4 cell count (below the threshold) at baseline was defined in different age categories as it varies in the different age groups of children. Therefore, it was defined as (for up to 12 months CD $4<1500$ / $\mathrm{mm}^{3}, 12-35$ months $<750 / \mathrm{mm}^{3}, 36-59$ months $<350$ / $\mathrm{mm}^{3}$, and $\geq 5$ years $<200 / \mathrm{mm}^{3}$ ) as it was defined from primary studies included in the analysis [16-23].

\section{Data analysis}

A weighted inverse variance random effects model [24] was used to estimate the proportion of mortality among children on ART and the odds ratio of hemoglobin and CD4 count. The variation in the pooled estimates of the proportion of mortality among children on ART was adjusted through subgroup analysis by the region where the study conducted and time after and before the implementation of test and treat strategies of ART treatment. Heterogeneity among included studies was checked using $I^{2}$ statistics where 25,50 , and $75 \%$ represent low, moderate, and high heterogeneity, respectively [25]. To assess the presence of publication bias, funnel plot and Egger's regression test were used. Trim and fill analysis were conducted to manage the publication bias. Moreover, a sensitivity analysis was conveyed to check the stability of the summary estimate. We used STATA version 11 statistical software to conduct this meta-analysis.

\section{Result}

\section{Literature search results}

We found a total of 6480 articles from different electronic databases (PubMed, EMBASE, Google Scholar, and Web of Science) and manual searching from Ethiopian university repository and reference lists of screened studies of which 22 were removed because of duplicates. By reviewing the titles and abstracts, 6198 and 179 were excluded from analysis, respectively. Finally, 16 articles were considered as fitted for the analysis from 81 studies

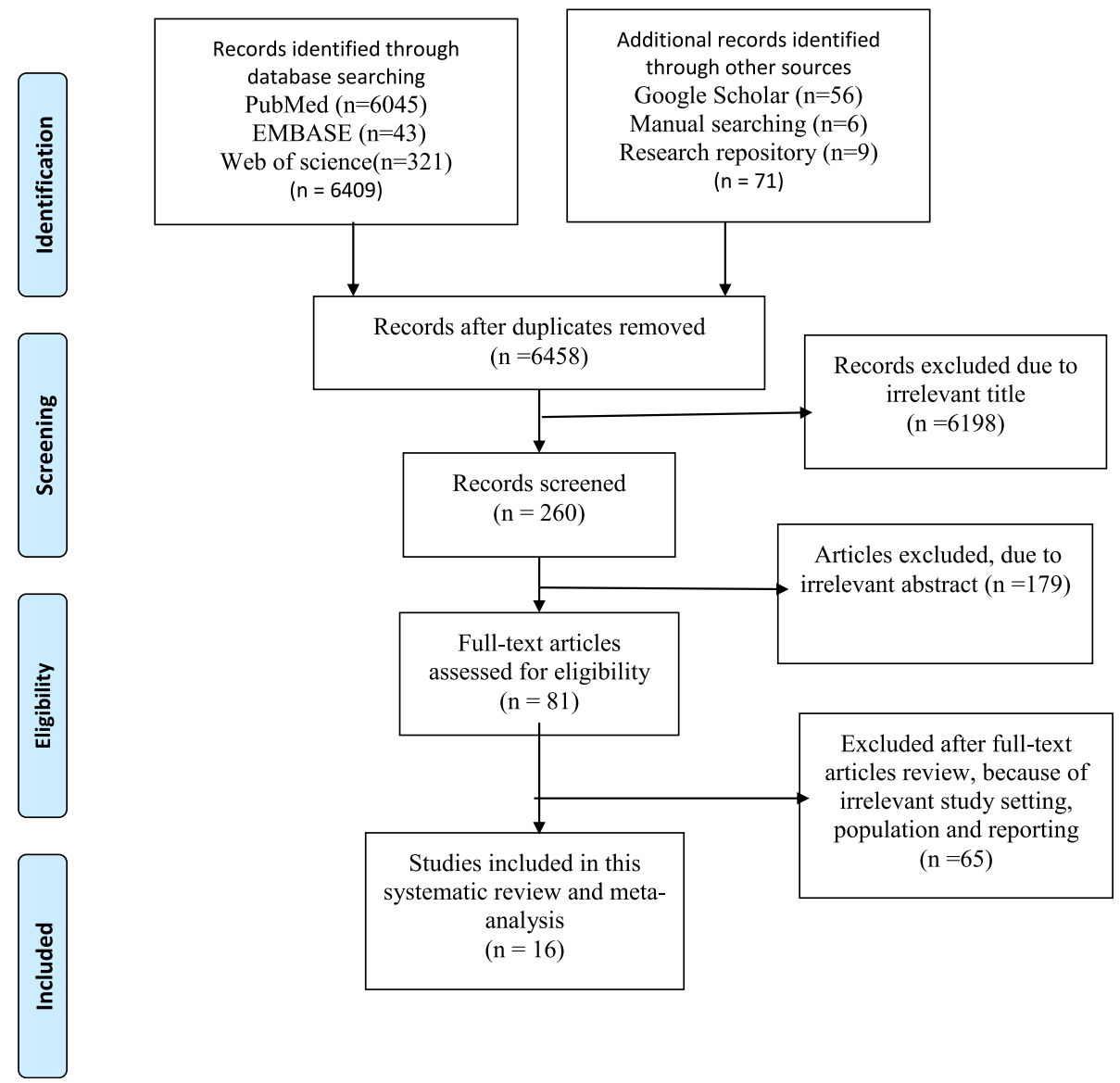

Fig. 1 Flow diagram of articles selection and screening process 
Table 1 Characteristics of included studies that reported the proportion of child mortality $(n=16)$

\begin{tabular}{|c|c|c|c|c|c|c|c|c|}
\hline Author & $\begin{array}{l}\text { Year of } \\
\text { publication }\end{array}$ & Region & $\begin{array}{l}\text { Follow-up } \\
\text { period }\end{array}$ & Study design & $\begin{array}{l}\text { Study } \\
\text { population }\end{array}$ & Sample size & $\begin{array}{l}\text { Number of } \\
\text { outcome }\end{array}$ & Percent (\%) \\
\hline Koye et al. & 2012 & Amhara & $2006-2011$ & Retrospective cohort & $<15$ year & 549 & 41 & 7.50 \\
\hline Gebremedhin et al. & 2013 & Tigray & 2006-2011 & Retrospective cohort & $<15$ year & 416 & 20 & 4.81 \\
\hline Taye et al. & 2010 & Addis Ababa & $2005-2008$ & Retrospective cohort & $<15$ year & 475 & 42 & 8.80 \\
\hline Asfawesen et al. & 2011 & Addis Ababa & $2005-2008$ & Retrospective cohort & $<15$ year & 482 & 13 & 7.50 \\
\hline Dube et al. & 2017 & Addis Ababa & $2008-2010$ & Retrospective cohort & $<15$ year & 757 & 51 & 6.70 \\
\hline Ebissa et al. & 2015 & Addis Ababa & $2008-2009$ & Retrospective cohort & 1-12 year & 556 & 58 & 10.40 \\
\hline Sidamo et al. & 2017 & SNNPRS & 2009-2016 & Retrospective cohort & $\leq 14$ year & 421 & 65 & 15.40 \\
\hline Biru et al. & 2018 & Addis Ababa & 2014-2016 & Prospective cohort & $<14$ year & 304 & 6 & 25.00 \\
\hline Atnafu and Wencheko & 2012 & Amhara & 2007-2009 & Retrospective cohort & $<15$ year & 255 & 71 & 27.84 \\
\hline Netsanet et al & 2009 & Oromia & $2005-2008$ & Retrospective cohort & $<14$ year & 96 & 7 & 7.30 \\
\hline Andargie et al. & 2018 & Amhara & 2008-2013 & Retrospective cohort & $<15$ year & 269 & 46 & 17.10 \\
\hline Edessa & 2015 & Harari & 2010-2013 & Retrospective cohort & $<15$ year & 305 & 28 & 9.20 \\
\hline Kedir & 2014 & Oromia & $2006-2010$ & Retrospective cohort & $<14$ year & 560 & 43 & 7.60 \\
\hline Mokgatle et al. & 2016 & Addis Ababa & 2005-2012 & Retrospective cohort & $<15$ year & 786 & 62 & 7.90 \\
\hline Alebel et al. & 2018 & Amhara & 2012-2017 & Retrospective cohort & $<15$ year & 390 & 38 & 9.70 \\
\hline Arage et al. & 2019 & Amhara & $2005-2015$ & Retrospective cohort & $<15$ year & 426 & 97 & 22.90 \\
\hline
\end{tabular}

selected for full-text review. The details of selection process articles are described in (Fig. 1).

\section{Characteristics of included studies}

On the whole, 16 studies with 7047 study participants had been included in the study. Except for one study which is a prospective follow cohort study [26], the remaining 15 studies were retrospectively followed up [16-23, 27-33]. All of the studies had been conducted from 2005 to 2017 in different follow-up periods with a maximum of 10 years and a minim of 1 year. Articles published between 2009 and 2019 were included in this review (Table 1).

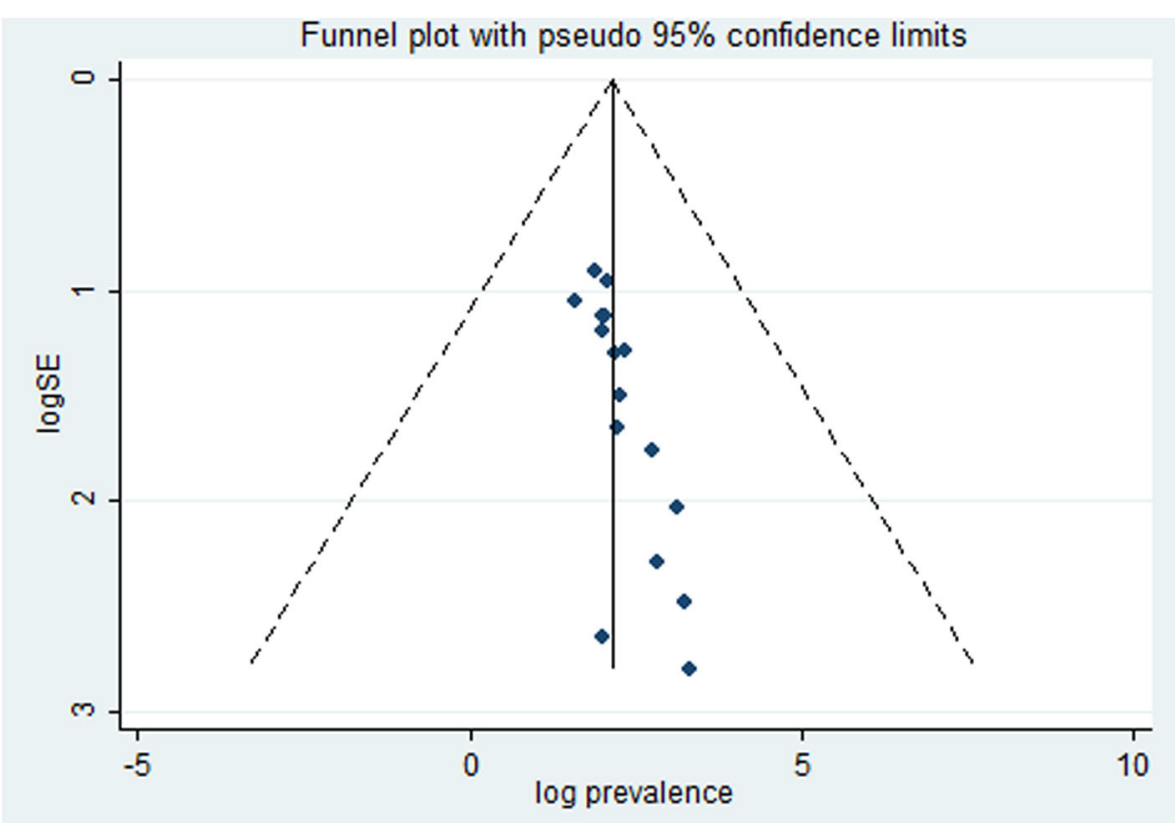

Fig. 2 Funnel plot for publication bias. Log prevalence and logSE represented the log of the prevalence in the $x$-axis and log of the standard error in the $y$-axis, respectively 


\section{Quality of included studies}

We found that all of the 16 studies included in this analysis were followed up; for this reason, the quality was assessed with the JBI quality appraisal checklist for follow-up studies, and studies that scored above 50\% were considered as low risk and none of them were excluded after assessing the quality of studies. The result of the quality assessment ranges from 62.5 to $75 \%$ (Additional file 3).

\section{Meta-analysis}

To assess the presence of publication bias, the funnel plot and Egger's regression test were performed. Egger's regression test was statically significant $(0.000)$ which revealed the presence of publication bias. To handle this bias, trim and fill analysis was performed. Consequently, two articles have been added in the fill stage (Fig. 2).

\section{Mortality}

The overall pooled proportion of mortality after a trim and fill analysis among children on ART was 9.785\% (95\% CI 7.029, 2.542). Before meta-trim and fill analysis was performed, the pooled proportion of child mortality was $11.78 \%$ (95\% CI 9.34, 14.23). However, due to the presence of statically significant publication bias, metatrim and fill analysis was conducted. Hence, two articles were filled and the proportion of mortality became 9.785\% (95\% CI 7.029, 2.542) (Fig. 3).

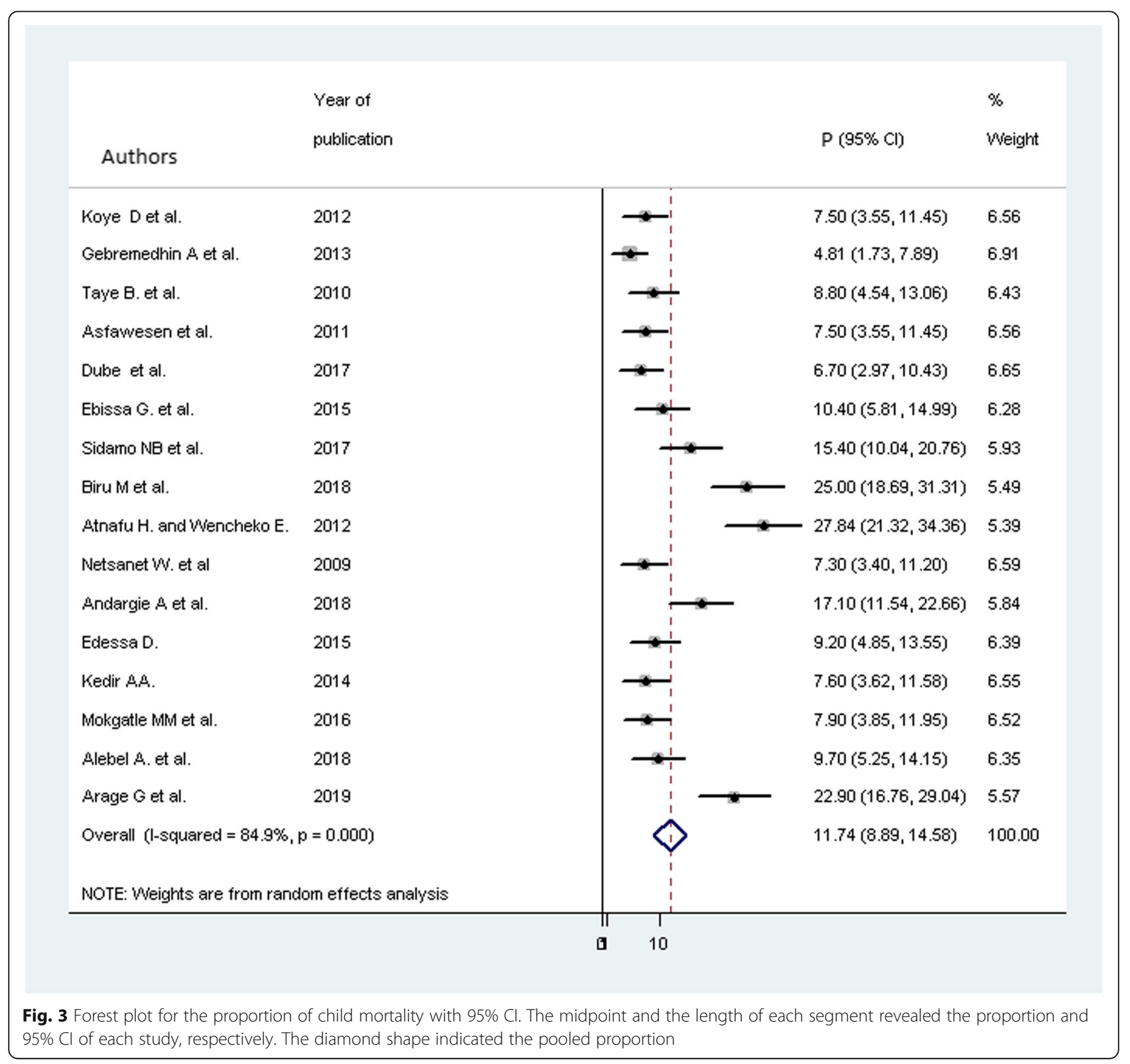




\section{Subgroup analysis}

Subgroup analysis was conducted by using the region and year of the primary studies published. From all studies which reported proportion of child mortality after ART initiation, 6 were from Addis, Ababa [18, 26-29, 33], 5 from Amhara [16, 20-23], 2 from Oromia [30, 32], 1 from Tigray [17], 1 from SNNPRS [19], and 1 from Harari [31]. In the subgroup analysis, the highest pooled proportion of mortality was reported in the Amhara region 16.76\% (95\% CI 9.63, 23.90) and the lowest in the Tigray $4.81 \%$ (95\% CI $2.75,6.87)$; subsequently, in Addis Ababa $10.43 \%$ (95\% CI $7.29,13.56)$, in Oromia $7.55 \%$ ( $95 \%$ CI $5.53,9.58)$, in SNNPRS $15.40 \%$ (95\% CI 11.95 , 18.85), and in Harari 9.20\% (95\% CI 5.96, 12.44) were found (Fig. 4).

On the other hand, subgroup analysis was conducted by year of publication and categorized into two divisions, in which articles published between 2009 and 2013 were in one group and 2014 and 2019 in the other group. From this analysis, the proportion of mortality during articles published from 2009 to 2013 and 2014 to 2019 was $10.05 \%$ (95\% CI 6.08, 14.03 ) and $12.83 \%$ (95\% CI 9.65, 16.01), respectively (Fig. 5).

\section{The association between child mortality and baseline CD4 cell count}

From the total 16 studies included in the analysis of the pooled proportion of child mortality, 7 studies [16-22] for baseline CD4 cell count were eligible for analysis. Those children who had CD4 cell count below the threshold were $2.42(\mathrm{AOR}=2.42,95 \% \mathrm{CI} 1.65,3.56)$ times more likely to die compared with children having CD4 cell count above the threshold (Fig. 6).

\begin{tabular}{|c|c|c|c|}
\hline $\begin{array}{l}\text { Author/year } \\
\text { of fpublication }\end{array}$ & & $\mathrm{P}(95 \% \mathrm{Cl})$ & $\begin{array}{l}\% \\
\text { Weight }\end{array}$ \\
\hline Amhara & 1 & & \\
\hline Koye $D$ et al. & $\rightarrow i$ & $7.50(5.30 .9 .70)$ & 6.68 \\
\hline Atnafu $\mathrm{H}$. and Wencheko $\mathrm{E}$. & i & $27.84(22.34 .33 .34)$ & 5.20 \\
\hline Andargie $A$ et al. & & $17.10(12.60,21.60)$ & 5.70 \\
\hline Alebel A. et al. & $\rightarrow$ & $9.70(8.78 .12 .64)$ & 8.41 \\
\hline Arage $\mathrm{G}$ et al. & 1 & $22.90(18.91 .26 .89)$ & 5.94 \\
\hline Subtotal (I-squared $=95.2 \%, p=0.000$ ) & & $16.78(9.63,23.90)$ & 29.92 \\
\hline . & i & & \\
\hline Tigray & 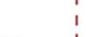 & & \\
\hline Gebremedhin A et al. & 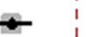 & $4.81(2.75 .6 .87)$ & 6.73 \\
\hline Subtotal (1-squared $=. \%, p=$. ) & 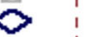 & $4.81(2.75 .6 .87)$ & 6.73 \\
\hline . & i & & \\
\hline Addis Ababa & i & & \\
\hline Taye B. et al. & $-i$ & $8.80(6.25 .11 .35)$ & 6.56 \\
\hline Asfawesen et al. & $\rightarrow \vdots$ & $7.50(5.15 .9 .85)$ & 6.63 \\
\hline Dube et al. & $\approx i$ & $6.70(4.92,8.48)$ & 6.81 \\
\hline Ebissa G. et al. & -1 & $10.40(7.86,12.94)$ & 6.56 \\
\hline Biru $M$ et al. & 1 & $25.00(20.13 .29 .87)$ & 5.51 \\
\hline Mokgatle MM et al. & $\leftarrow 1$ & $7.90(6.01 .9 .79)$ & 6.78 \\
\hline Subtotal (I-squared $=90.3 \%, p=0.000$ ) & & $10.43(7.29,13.58)$ & 38.85 \\
\hline . & 1 & & \\
\hline SNNPRS & i & & \\
\hline Sidamo NB et al. & 1 & $15.40(11.95 .18 .85)$ & 8.19 \\
\hline Subtotal (1-squared $=. \%, p=$. ) & & $15.40(11.95,18.85)$ & 6.19 \\
\hline . & i & & \\
\hline Oromia & 1 & & \\
\hline Netsanet $W$. et al & & $7.30(2.10 .12 .50)$ & 5.35 \\
\hline Kedir AA. & $i$ & $7.60(5.41 .9 .79)$ & 6.68 \\
\hline Subtotal (1-squared $=0.0 \%, p=0.917$ ) & $i$ & $7.55(5.53 .9 .58)$ & 12.03 \\
\hline & i & & \\
\hline Harari region & $i$ & & \\
\hline Edessa $D$. & - & $9.20(5.96 .12 .44)$ & 6.28 \\
\hline Subtotal (1-squared $=. \%, p=$ ) & & $9.20(5.96 .12 .44)$ & 6.28 \\
\hline . & & & \\
\hline Overall (l-squared $=92.1 \%, p=0.000$ ) & $<$ & $11.78(9.34,14.23)$ & 100.00 \\
\hline NOTE: Weights are from random effects anslysis & i & & \\
\hline & 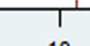 & & \\
\hline
\end{tabular}

Fig. 4 Forest plot for subgroup analysis of the proportion of child mortality by region. The midpoint and the length of each segment showed the proportion and $95 \% \mathrm{Cl}$ of each study, respectively. The diamond shape revealed the pooled proportion of child mortality in each region 


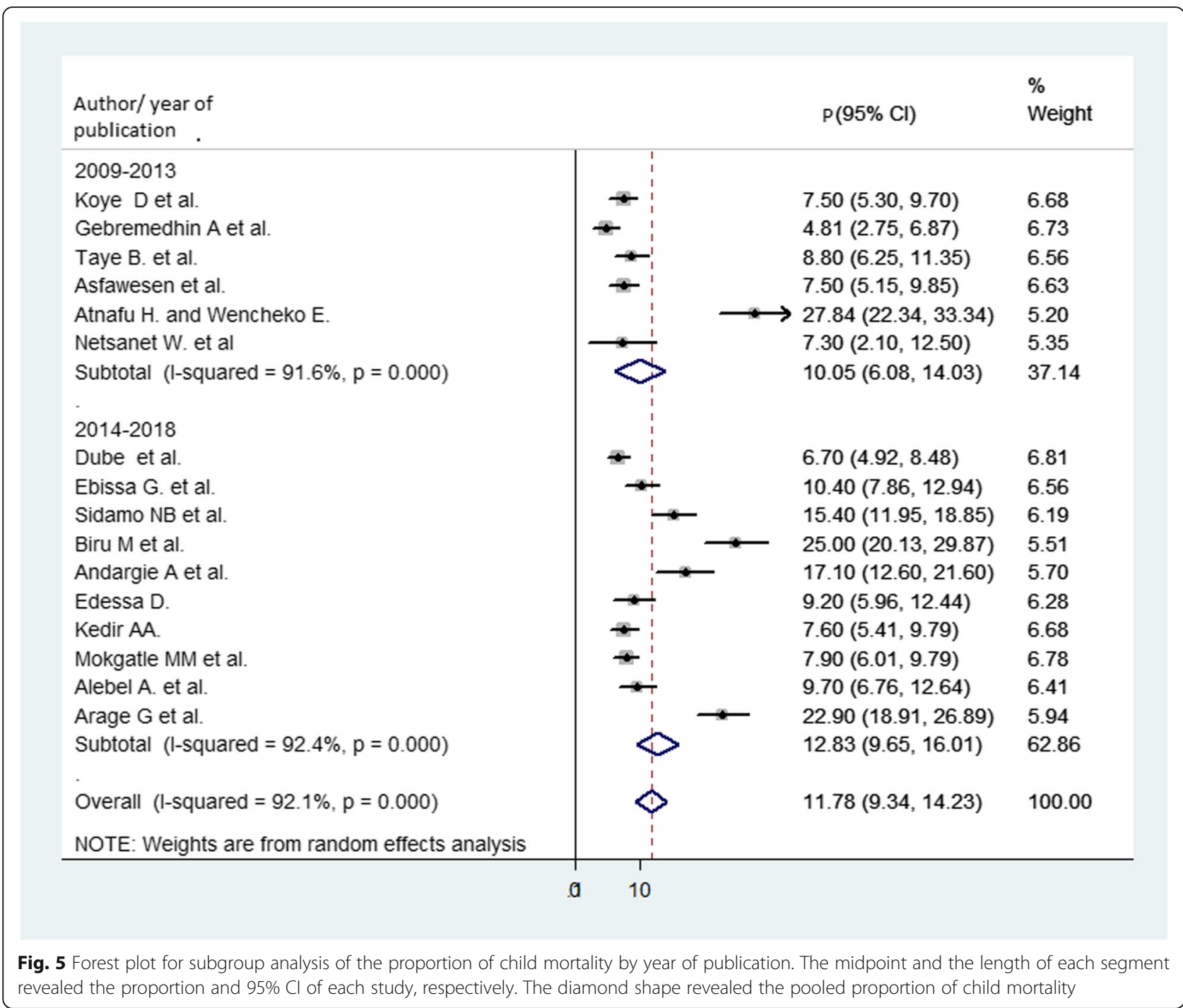

\section{The association between child mortality and baseline} hemoglobin level

A total of 7 studies [16, 18-23] were used in the analysis. The overall pooled odds ratio of mortality among children who had hemoglobin level less than $10 \mathrm{~g} / \mathrm{dl}$ were 3.24 ( $\mathrm{AOR}=3.24,95 \% \mathrm{CI} 1.51,6.93)$ more likely to die compared with children whose hemoglobin level was $10 \mathrm{~g} / \mathrm{dl}$ and above (Fig. 7).

\section{Discussion}

Child mortality is one of the global topics and is an indicator of the countries' development. Even though there is good progress in the reduction of child mortality, still a large number of children die from this preventable disease [3]. Infectious diseases including HIV takes the major share for child mortality in Ethiopia. Therefore, this systematic review and meta-analysis is aimed to estimate child mortality due to HIV and contributing factors after the initiation of ART in Ethiopia.

This study revealed that $11.78 \%$ (95\% CI 9.34, 14.23) of children died due to causes related to HIV infection after starting ART in Ethiopia. Nearly one of every twelve children is dead due to HIV infection and other related complications in Ethiopia. The result is slightly higher than the previous study conducted in SSA (7.9\%) [14]. On the contrary, the finding of this study was lower than a systematic review conducted in low- and middleincome countries on the retention of pediatric patients on HIV treatment. The review reported that (37\%) pediatric patients that were not in care are known to be dead [34]. This discrepancy might be because of the difference in the study periods. In addition, in the current systemic review and meta-analysis, most included articles was conducted in recent years after different interventions had been implemented to reduce 


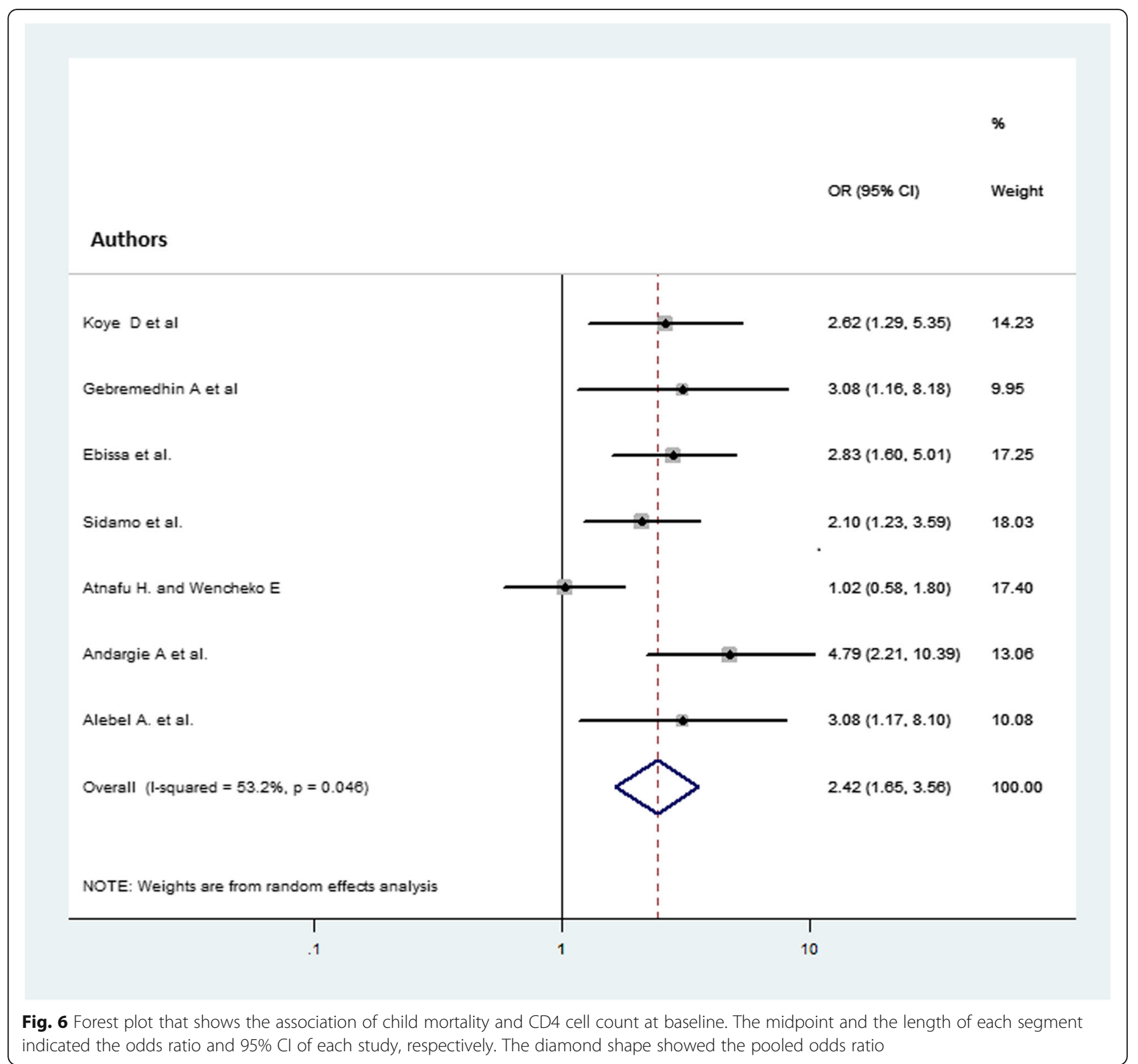

mortality like test and treat and treat all strategies. These interventions have shown a significant reduction in mortality of children $[4,35,36]$.

As a result of significant heterogeneity among studies, subgroup analysis was conducted by considering regional variation. As a result, the highest proportion of mortality was reported in the Amhara region (16.76\%) followed by the SNNPRS region (15.4\%), and the lowest proportion was observed in the Tigray region $(4.81 \%)$. In addition to the proportion of death, this study also showed the impact of low hemoglobin level and CD4 cell count at baseline on mortality of children taking ART in Ethiopia. The findings indicated that those children who had low hemoglobin levels and CD4 cell count below the threshold at baseline were more likely to die compared with children who had a normal value.

Those children who had low hemoglobin levels were three times more likely to die as compared with children who had $10 \mathrm{~g} / \mathrm{dl}$ and above hemoglobin level at baseline $(\mathrm{AOR}=3.24,95 \%$ CI 1.51, 6.93). Those children having low hemoglobin levels below $10 \mathrm{~g} / \mathrm{dl}$ are anemic at baseline. Anemia is one of the comorbidities that cause a significant number to die especially in children [37]. The presence of anemia is one of the indicators for underlying undiagnosed and untreated comorbidity in children which need early diagnosis and treatment as equivalent to HIV treatment. On the other hand, some ART drugs can cause anemia directly. Especially, for those children having anemia at baseline, the condition will be 


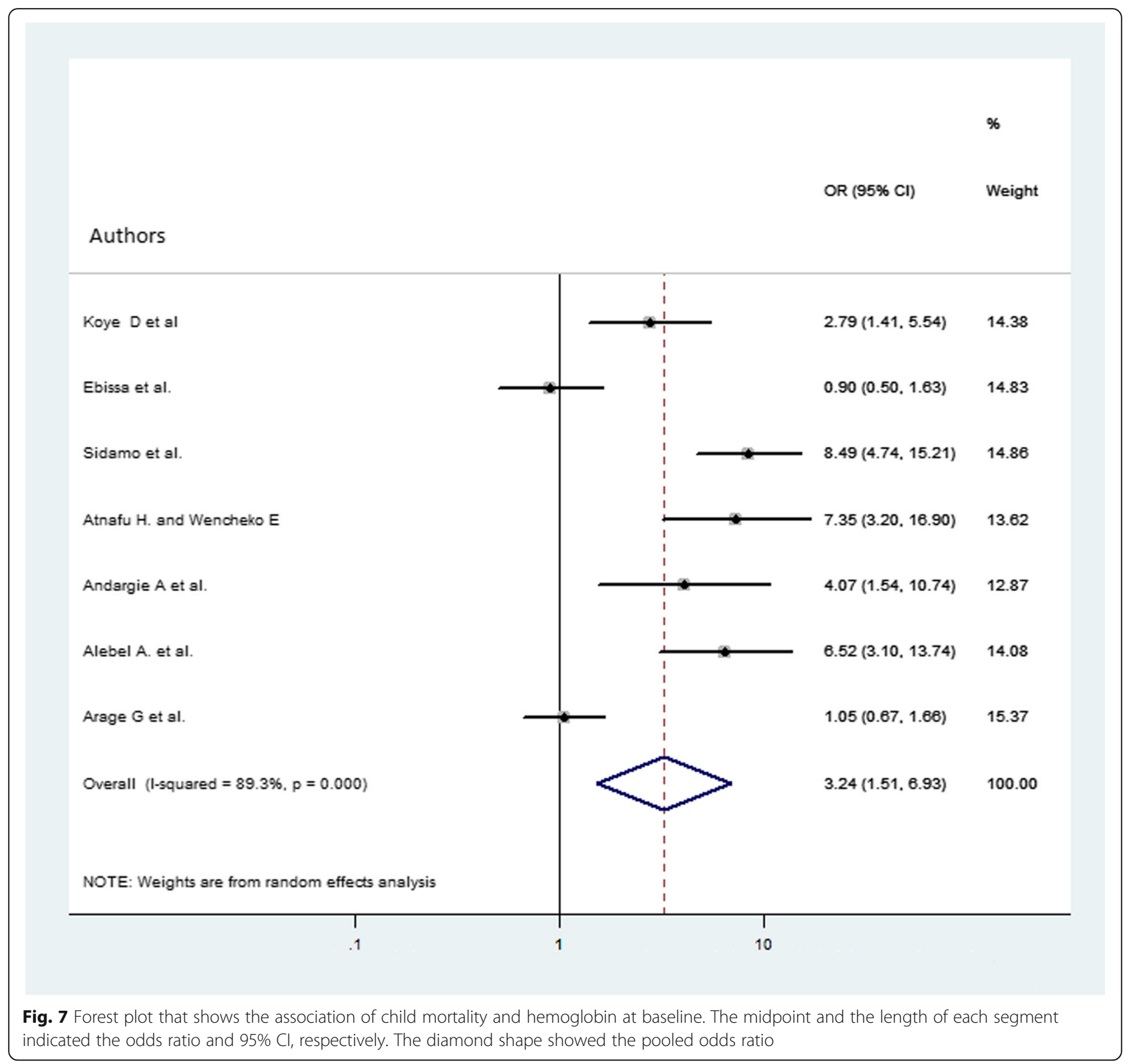

aggravated with the drug side effects [38-41]. Besides this, the presence of anemia may indicate underlying nutritional problems which is the other major cause of child mortality in developing countries [42-44].

The other predictor of mortality was low CD4 cell count below the threshold at baseline. Those children who had low CD4 cell count at baseline was 2.4 times more likely to die compared with those who had CD4 cell count above the threshold $(\mathrm{AOR}=2.42,95 \% \mathrm{CI}$ 1.65, 3.56). Those children having low CD4 cell count at baseline are exposed to a different infection that leads to different complications and finally leads to death [45, 46]. In Ethiopia, infectious diseases are the leading cause of death in children [12]. Infectious diseases are more severe and fatal in immunocompromised children than non-HIV-infected children [10]. As a result of low CD4 cell count, even the normal flora of the body can cause serious infections and complications that lead to death in children infected with HIV. The ART drug cannot treat the already developed opportunistic infections unless the underlying infections are treated.

\section{Strength and limitation}

This study tried to show the national proportion of child mortality among children on ART in Ethiopia. Besides, this study showed that children who had low hemoglobin levels and CD4 cell count were more at risk for death compared with their counterparts. The study 
also has a limitation, and one of the limitations is it does not include representative papers in all regions of the country. In addition, we could not analyze more factors due to inconsistent measurements of factors and different operational definitions of variables.

\section{Conclusion}

In Ethiopia, the mortality of children was high after ART initiation. Moreover, the proportion of mortality is higher among children having low CD4 cell count below the threshold and hemoglobin level less than $10 \mathrm{~g} / \mathrm{dl}$ at baseline. Therefore, those children who had low CD4 cell count and low hemoglobin levels at baseline need special attention, treatment, and care.

\section{Supplementary information}

Supplementary information accompanies this paper at https://doi.org/10. 1186/s41182-020-00267-y.

Additional file 1. Preferred Reporting Items for Systematic Review and Meta-analysis (PRISMA) guideline.

Additional file 2. Search strategy.

Additional file 3. JBI critical appraisal checklist.

\section{Abbreviations}

AIDS: Acquired immune deficiency syndrome; AOR: Adjusted odds ratio; ART: Antiretroviral therapy; HAART: Highly active antiretroviral therapy; Hgb: Hemoglobin; HIV: Human immunodeficiency virus; JBI: Joanna Briggs Institute; PRISMA: Preferred Reporting Items for Systematic Review and Meta-analysis; SNNPRS: South Nation and Nationality Peoples Regional State; SSA: Sub-Saharan Africa; WHO: World Health Organization

\section{Acknowledgements}

We need to give recognition to the primary authors of the included studies, which serve as a source of information to conduct this systematic review and meta-analysis.

\section{Authors' contributions}

CAW conceived and designed it first. Both authors, CAW and GMB, developed the search strategy, extracted the data, assessed the quality of included articles, performed the analysis, and the prepared the manuscript. Finally, the two authors read, modified, and agreed on the final manuscript submitted.

\section{Funding}

No funding has been received to conduct this systematic review and metaanalysis.

\section{Availability of data and materials}

All data generated and analyzed in the analysis process have been included in this manuscript.

\section{Ethics approval and consent to participate}

It is not applicable since we used previously conducted studies.

\section{Consent for publication}

It is not applicable since we used already published data.

\section{Competing interests}

The two authors declare that they have no conflict of interests.
Received: 14 June 2020 Accepted: 14 September 2020

Published online: 21 September 2020

\section{References}

1. UNAIDS Global HIV. AIDS statistics - 2019 fact sheet (2019).

2. Joint United Nations Programme on HIV/AIDS. Global HIV \& AIDS statistics-2018 fact sheet. 2019.

3. Estimation UNI-aGfCM, Hug L, Sharrow D, Zhong K, You D, et al, Unicef. Levels \& Trends in Child Mortality: Report 2018, Estimates developed by the: United Nations Children's Fund; 2018.

4. World Health Organization. Consolidated guidelines on the use of antiretroviral drugs for treating and preventing HIV infection: recommendations for a public health approach: World Health Organization; 2016.

5. Burrage A, Patel M, Mirkovic K, Dziuban E, Teferi W, Broyles L, et al. Trends in antiretroviral therapy eligibility and coverage among children aged $<15$ years with HIV infection-20 PEPFAR-supported sub-Saharan African countries, 2012-2016. Morbidity and Mortality Weekly Report. 2018; 67(19):552.

6. Puthanakit T, Bunupuradah T. Early versus deferred antiretroviral therapy in children in low-income and middle-income countries. Current Opinion in HIV and AIDS. 2010;5(1):12-7.

7. Violari A, Cotton MF, Gibb DM, Babiker AG, Steyn J, Madhi SA, et al. Early antiretroviral therapy and mortality among HIV-infected infants. New England Journal of Medicine. 2008;359(21):2233-44.

8. Anigilaje EA, Aderibigbe SA. Mortality in a cohort of HIV-infected children: a 12-month outcome of antiretroviral therapy in Makurdi, Nigeria. Advances in medicine. 2018;2018.

9. Edmonds A, Yotebieng M, Lusiama J, Matumona Y, Kitetele F, Napravnik S, et al. The effect of highly active antiretroviral therapy on the survival of HIVinfected children in a resource-deprived setting: a cohort study. PLoS medicine. 2011;8:6.

10. Desmonde S, Coffie P, Aka E, Amani-Bosse C, Messou E, Dabis F, et al. Severe morbidity and mortality in untreated HIV-infected children in a paediatric care programme in Abidjan, Cote d'Ivoire, 2004-2009. BMC infectious diseases. 2011;11(1):182.

11. UNAIDS GH, Statistics A. 2018 Fact Sheet, 2019. 2019.

12. Deribew A, Biadgilign S, Deribe K, Dejene T, Tessema GA, Melaku YA, et al. The burden of HIV/AIDS in Ethiopia from 1990 to 2016: Evidence from the Global Burden of Diseases 2016 Study. Ethiopian journal of health sciences. 2019;29:1.

13. Susuman AS. HIV/AIDS in Ethiopia: Health View. Journal of Asian and African studies. 2015,

14. Ahmed I, Lemma S. Mortality among pediatric patients on HIV treatment in sub-Saharan African countries: a systematic review and meta-analysis. BMC public health. 2019;19(1):149.

15. Liberati A, Altman DG, Tetzlaff J, Mulrow C, Gøtzsche PC, loannidis JP, et al. The PRISMA statement for reporting systematic reviews and meta-analyses of studies that evaluate health care interventions: explanation and elaboration. Annals of internal medicine. 2009;151(4):W-65-94.

16. Koye DN, Ayele TA, Zeleke BM. Predictors of mortality among children on antiretroviral therapy at a referral hospital, Northwest Ethiopia: a retrospective follow up study. BMC pediatrics. 2012;12(1):161.

17. Gebremedhin A, Gebremariam S, Haile F, Weldearegawi B, Decotelli C. Predictors of mortality among HIV infected children on anti-retroviral therapy in Mekelle Hospital, Northern Ethiopia: a retrospective cohort study. BMC public health. 2013;13(1):1047.

18. Ebissa G, Deyessa N, Biadgilign S. Predictors of early mortality in a cohort of HIV-infected children receiving high active antiretroviral treatment in public hospitals in Ethiopia. AIDS care. 2015;27(6):723-30

19. Sidamo N, Debere M, Enderis B, Abyu D. Incidence and Predictors of Mortality among Children on Anti-Retroviral Therapy in Public Health Facilities of Arba Minch Town, Gamo Gofa Zone, Southern Ethiopia; Retrospective Cohort Study. Clinics Mother Child Health. 2017;14(267):2.

20. Atnafu $\mathrm{H}$, Wencheko E. Factors affecting the survival of HIV-infected children after ART initiation in Bahir-Dar, Ethiopia. Ethiopian Journal of Health Development. 2012;26(3):193-9.

21. Andargie AA, Asmleash Y. Survival time of human immunodeficiency virus (HIV) infected children under 15 years of age after initiation of antiretroviral therapy in the University of Gondar Comprehensive Specialized Hospital, Ethiopia. J AIDS HIV Res. 2018;10(4):49-55. 
22. Alebel A, Wagnew F, Tesema C, Kibret GD, Petrucka P, Eshite S. Effects of undernutrition on survival of human immunodeficiency virus positive children on antiretroviral therapy. Italian journal of pediatrics. 2018;44(1):29.

23. Arage G, Assefa M, Worku T, Semahegn A. Survival rate of HIV-infected children after initiation of the antiretroviral therapy and its predictors in Ethiopia: a facility-based retrospective cohort. SAGE open medicine. 2019;7: 2050312119838957.

24. DerSimonian R, Kacker R. Random-effects model for meta-analysis of clinical trials: an update. Contemporary clinical trials. 2007;28(2):105-14.

25. Higgins JP, Thompson SG, Deeks JJ, Altman DG. Measuring inconsistency in meta-analyses. Bmj. 2003;327(7414):557-60.

26. Biru $M$, Hallström I, Lundqvist $P$, Jerene $D$. Rates and predictors of attrition among children on antiretroviral therapy in Ethiopia: a prospective cohort study. Plos one. 2018;13:2.

27. Taye B, Shiferaw S, Enquselassie F. The impact of malnutrition in survival of HIV infected children after initiation of antiretroviral treatment (ART). Ethiopian medical journal. 2010;48(1):1-10.

28. Asfawesen G, Solomie J, Bisirat T, Berhanu G, Mebratu B, Rahlenbeck S. Outcome in a paediatric cohort receiving ART in Addis Abeba, Ethiopia. Acta Paediatrica. 2011;100(8):1164-7.

29. Mulugeta A, Assefa H, Tewelde T, Dube L. Determinants of Survival among HIV Positive Children on Antiretroviral Therapy in Public hospitals, Addis Ababa, Ethiopia. Quality in Primary Care. 2017;25(4):235-41.

30. Workneh N, Girma T, Woldie M. Immunologic and clinical outcomes of children on HAART: a Retrospective cohort analysis at Jimma University specialized hospital. Ethiopian Journal of Health Sciences. 2009;19:2.

31. Edessa D, Asefa F, Sheikahmed J. Early mortality among HIV-positive children initiated anti-retroviral therapy in eastern Ethiopia: a retrospective cohort study. Science, Technology and Arts Research Journal. 2015;4(2):157-63.

32. Kedir A, Desta A, Fesseha G. Factors affecting survival of HIV positive children taking antiretroviral therapy at Adama Referral Hospital and Medical College, Ethiopia. J AIDS Clin Res. 2014;5(3):1-6.

33. Mokgatle MM, Abasho DC. Treatment outcomes of antiretroviral therapy among pediatric patients in Zewditu memorial hospital, Addis Ababa, Ethiopia. PULA: Botswana J Afr Stud. 2016;30(1):11.

34. Fox MP, Rosen S. Systematic review of retention of pediatric patients on HIV treatment in low and middle-income countries 2008-2013. Aids. 2015;29(4): 493-502.

35. HIV/AIDS JUNPO. 90-90-90: an ambitious treatment target to help end the AIDS epidemic. Geneva: Joint United Nations Programme on HIV. Aids. 2014:33.

36. Organization WH. Policy brief: Consolidated guidelines on HIV prevention, diagnosis, treatment and care for key populations. World Health Organization, 2017.

37. Wagnew F, Eshetie S, Alebel A, Tesema C, Kibret GD, Gebrie A, et al. Burden of anemia and its association with HAART in HIV infected children in Ethiopia: a systematic review and meta-analysis. BMC Infectious Diseases. 2019;19(1):1032.

38. Shet A, Arumugam K, Rajagopalan N, Dinakar C, Krishnamurthy S, Mehta S, et al. The prevalence and etiology of anemia among HIV-infected children in India. European journal of pediatrics. 2012;171(3):531-40.

39. Wolde HM. Incidence and risk factors of anemia among HIV/AIDS patients taking anti-retroviral erapy at tertiary hospitals in Addis Ababa, Ethiopia: a retrospective cohort study. J HIV AIDS Infect Dis. 2014;2:1-06.

40. Verma D, Acharya A, Bachani D, Seth A, Hemal A. Effect of ART on anemia in children living with HIV attending tertiary care hospitals of New Delhi. Indian Journal of Community Health. 2014;26(Supp 2):258-63.

41. Ssali F, Stöhr W, Munderi P, Reid A, Walker AS, Gibb DM, et al. Prevalence, incidence and predictors of severe anaemia with zidovudine-containing regimens in African adults with HIV infection within the DART trial. 2006.

42. Hussen S, Belachew T, Hussien N. Nutritional status and its effect on treatment outcome among HIV infected clients receiving HAART in Ethiopia: a cohort study. AIDS research and therapy. 2016;13(1):32.

43. Paton NI, Sangeetha S, Earnest A, Bellamy R. The impact of malnutrition on survival and the CD4 count response in HIV-infected patients starting antiretroviral therapy. HIV medicine. 2006;7(5):323-30.

44. Oumer A, Kubsa ME, Mekonnen BA. Malnutrition as predictor of survival from anti-retroviral treatment among children living with HIV/AIDS in Southwest Ethiopia: survival analysis. BMC pediatrics. 2019;19(1):474.
45. Gershon AA, Mervish N, LaRussa P, Steinberg S, Lo SH, Hodes D, et al. Varicella-zoster virus infection in children with underlying human immunodeficiency virus infection. Journal of Infectious Diseases. 1997; 176(6):1496-500.

46. Mao C, Harper M, McIntosh K, Reddington C, Cohen J, Bachur R, et al. Invasive pneumococcal infections in human immunodeficiency virusinfected children. Journal of Infectious Diseases. 1996;173(4):870-6.

\section{Publisher's Note}

Springer Nature remains neutral with regard to jurisdictional claims in published maps and institutional affiliations.
Ready to submit your research? Choose BMC and benefit from:

- fast, convenient online submission

- thorough peer review by experienced researchers in your field

- rapid publication on acceptance

- support for research data, including large and complex data types

- gold Open Access which fosters wider collaboration and increased citations

- maximum visibility for your research: over $100 \mathrm{M}$ website views per year

At BMC, research is always in progress.

Learn more biomedcentral.com/submissions 